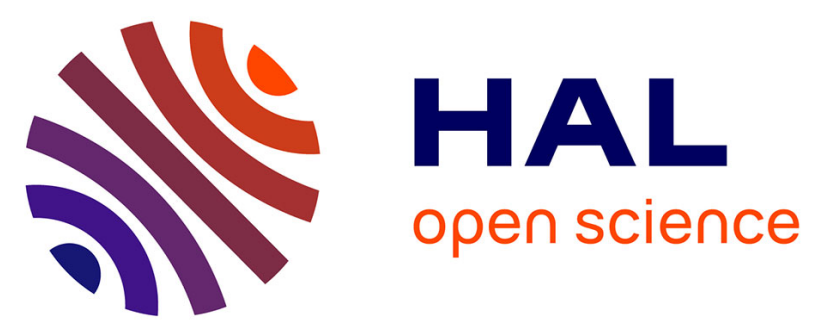

\title{
Computational and Human Intelligence in Blind Go.
}

Ping-Chiang Chou, Hassen Doghmen, Chang-Shing Lee, Fabien Teytaud,

Olivier Teytaud, Hui-Ching Wang, Mei-Hui Wang, Shi-Jim Yen, Wen-Li Wu

\section{To cite this version:}

Ping-Chiang Chou, Hassen Doghmen, Chang-Shing Lee, Fabien Teytaud, Olivier Teytaud, et al.. Computational and Human Intelligence in Blind Go.. Computational Intelligence and Games, Aug 2011, Seoul, North Korea. inria-00625849

\section{HAL Id: inria-00625849 \\ https://hal.inria.fr/inria-00625849}

Submitted on 22 Sep 2011

HAL is a multi-disciplinary open access archive for the deposit and dissemination of scientific research documents, whether they are published or not. The documents may come from teaching and research institutions in France or abroad, or from public or private research centers.
L'archive ouverte pluridisciplinaire HAL, est destinée au dépôt et à la diffusion de documents scientifiques de niveau recherche, publiés ou non, émanant des établissements d'enseignement et de recherche français ou étrangers, des laboratoires publics ou privés. 


\title{
Computational and Human Intelligence in Blind Go.
}

\author{
Ping-Chiang Chou, Hassen Doghmen, Chang-Shing Lee, Fabien Teytaud, Olivier Teytaud, Hui-Ming Wang, \\ Mei-Hui Wang, Li-Wen Wu, Shi-Jim Yen,
}

\begin{abstract}
In this paper, we will consider questions related to blindfolded play: (i) the impact (in various conditions) of playing blindfolded in the level of Go players in 9x9 Go (ii) the influence of a visual support (the visual support is a board with no stone) (iii) which modifications are required for making a program strong in the blind variant of the game (and, somehow surprisingly, implementing a program for playing blind go is not equivalent to implementing a program for playing go) (iv) some conclusions on the rules of blind Go for making it interesting and pedagogically efficient.
\end{abstract}

\section{INTRODUCTION}

Board games are, most often (but not always, see [1]), fully observable; theoretically, just from the sequence of moves, it is possible to recover all the information, and therefore, to play optimally - the visual support is useless. However, it is clear that the visual support is highly necessary for most players.

Yet, strong players develop a special memory, which is less based on the visual support; in chess, strong players can play with moderate decay of performance[2], [3]. Many players can even play simultaneous blindfolded chess. However, not all strong chess players are strong blindfold chess players.

Blindfolded board games go back to the seven century according to Wikipedia (blindfold chess); Wikipedia also states that it was later considered as a good tool for occupying nights for people having trouble sleeping, for playing chess while working for Asian horsemen, for earning money by showing superior abilities, and even for learning chess by forcing a strong focus on the game. To the best of our knowledge, the fact that playing chess is a good tool for learning blindfold chess is clearly established (as many strong players can play blind chess without or with little specific training), but the fact that playing blind chess is a good tool for learning chess itself, or for anything else, is unclear. The same can be said for blind Go.

In the game of Go, playing without visual support is much more difficult in 19x19. To the best of our knowledge, only Bao Yun (Chinese 6D, no sight trouble) and Pierre Audouard (French 5D, with severe and increasing sight loss) are able to play a complete game. However, the $9 \times 9$ form of the game is easily played by many strong players, even without training. This paper reports results of blind 9x9 games between P.-C. Chou (5P) and C.-H. Chou (9P) and MoGoTW, a strong Go program.

In this paper, we investigate the following questions:

H. Doghmen, F. Teytaud and O. Teytaud are with TAO (Inria), LRI, UMR Cnrs 8623 Univ. Paris-Sud, France; S.-J. Yen is with the National Dong Hwa University, Taiwan; C.-S. Lee, H.-M. Wang, M.-H. Wang, L.-W. Wu are with the National University of Tainan, Taiwan; P.C. Chou is wit the Taiwan Go Association.
- Computational intelligence design question: should a program play differently against a human opponent than against a computer? Our hypothesis here is that the same-strength assumption, which is the basis for many computer programs (alpha-beta or Monte-Carlo Tree Search) does not hold in blind games. Two counterexamples to this "same strength" assumption are already known in some non-blindfolded games:

- It is known ([4]) that in (non-blindfolded) chess, computers should play differently when they play against a human and when they play against a computer: this is because humans are weak in endgames (compared to computers) and therefore the computer should accept a sacrifice which leads to a draw endgame, if this endgame is too hard for humans.

- Also, as humans are poor random generators, computers are stronger than humans in repeated RockPaper-Scissors and computers should not play the Nash equilibrium.

We will argue that the same phenomenon occurs in blindfolded board games: even in games (like Go) in which computers are weaker than humans, they can benefit from human's biases by playing very complicated moves which are difficult to memorize for humans.

- Challenge: are computers stronger than humans in 9x9 blind Go? We are roughly at the point at which computers are close to the best human levels in 9x9 Go, but they have still troubles for winning as black and do not win all their games as white; we'll see that things are seemingly better for computers in 9x9 blind Go. Yet, more games are required for claiming this with certainty. Our hypothesis here is that even very strong humans are usually weaker in blind games, even in the $9 x 9$ form of the game.

- Serious games, pedagogical aspects: Go players are often extremely careful about their board and stones. Also, while simulating possible futures of the current state on a secondary board, or using pen and paper, is forbidden during a Go game, many players simulate random games in their mind's eye when thinking. Also, whenever go players are playing blindfolded, they request a board which is not too far from their usual board. ${ }^{1}$ This is related to works emphasizing the necessity of a priori useless auxiliary visual stimuli for learning efficiently in simulated conditions; see [5]

\footnotetext{
${ }^{1}$ These authors have seen several times their boards rejected by human players due to insufficient quality.
} 
for bicycle simulators. Our assumption is that a visual support (empty board) is important for playing blind go (maybe this influence is highly dependent on persons as there are various forms of memory even among people with very high skills[6]); the influence of the quality of the board (often mentioned by players) is left as further work.

We will test these assumptions both with amateurs (Section II) and with professional players (Section III). Finally, we will test the modifications suggested by these experiments in section IV.

\section{AMATEUR RESUlTS}

In section II-A we test the playing skills of blind-Go players depending on the visual support and on a simple modification of the Go playing program. In section II-B we test the memorization of standard openings compared to randomized openings, showing that the memorization part of blind Go is much harder in the case of a randomized or strange opening.

\section{A. Playing skills}

We tested amateurs' skills for playing 9x9 blind Go. The first test was in 9x9; but weak amateurs can hardly play a complete 9x9 game. We compared two cases: (i) with visual support (an empty grid) and (ii) without visual support. Games were playing alternatively in each condition, and results were as follows: 22, 26 and 18 legal moves with visual support, and 16, 20 and 18 legal moves without visual support. Results are therefore unclear, and it's not even possible to play a complete game.

We then switched to $5 \times 5$; it is known (http://

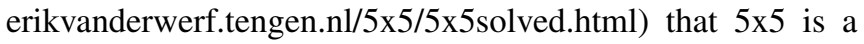
draw with komi 25 (black should kill every white stones on the board). We chose komi 24.5, and the human was black; therefore, in case of perfect play (which is possible even for amateur players in standard $5 \times 5$ Go) black should win; but any mistake leads to a loss (the computer will not fail in such a setting).

Results are presented in Table I (condition 1 corresponds to MoGoTW as opponent; condition 2 corresponds to the modified version proposed in section IV). The efficiency of the visual support, yet widely mentioned by human players, does not clearly appear (results are not significant), so we do not conclude on this; if there is an effect, maybe it is not that big after all for these amateur players.

As the amateur player \#2 was too strong for this exercise, we then switched to $7 \times 7$ and got results as presented in Table II.

The hypothesis "the probability of winning without visual support is $\geq$ the probability of winning with visual support" can be rejected with p-value $5.5 \%$ for the third experiment (by Fisher's exact test).

\section{B. Memorization}

[7] has shown that visual information with no structure (structure is necessary for long-term memory) can nonetheless last several seconds (i.e. more than the so-called iconic

\begin{tabular}{|c|c|c|}
\hline & $\begin{array}{c}\text { with } \\
\text { visual } \\
\text { support }\end{array}$ & $\begin{array}{c}\text { without } \\
\text { visual } \\
\text { support }\end{array}$ \\
\hline \multicolumn{3}{|c|}{ Amateur player \#1 } \\
\hline Condition 1 & $6 / 7$ & $4 / 6$ \\
Condition 2 & $2 / 7$ & $0 / 6$ \\
\hline \multicolumn{2}{|c|}{ Amateur player \#2 } \\
\hline Condition 1 & $5 / 5$ & $5 / 5$ \\
Condition 2 & $4 / 5$ & $5 / 5$ \\
\hline
\end{tabular}

TABLE I

RESULTS OF TESTS ON AMATEURS IN 5X5 BLIND GO. CONDITION 1 IS THE USUAL VERSION OF OUR MCTS PROGRAM MOGOTW, WHEREAS CONDITION 2 IS MODIFIED AS EXPLAINED IN SECTION IV.

\begin{tabular}{|l|c|c|}
\hline & $\begin{array}{c}\text { with } \\
\text { visual } \\
\text { support }\end{array}$ & $\begin{array}{c}\text { without } \\
\text { visual } \\
\text { support }\end{array}$ \\
\hline \multicolumn{3}{|c|}{ Amateur player \#2 } \\
\hline Condition 1 & $4 / 5$ & $1 / 5$ \\
Condition 2 & $0 / 2$ & - \\
\hline
\end{tabular}

TABLE II

RESUlts By AMATEUR PLAYER \#2 AGAinst MoGo With 50 SIMULATIONS PER MOVE. IN THE CONDITION 2 CASE, THE AMATEUR PLAYS TWO GAMES WITH VISUAL SUPPORT. DURING BOTH GAMES THE AMATEUR PLAYED CORRECTLY DURING A LONG PART OF THE GAME BUT FORGOT THE POSITION WHEN THE COMPUTER PLAYED MOVES WHICH ARE UNUSUAL IN STANDARD GO.

memory). Nonetheless, the capacity of this memory is moderate [8] (see also [9]) and exceptional memorizations are usually based on a huge knowledge and subtle memorization techniques; the "brute force" short term memory can not last for a full game.

It is known in chess that random positions are much harder to memorize than real positions. This suggests that it might be possible to make a program stronger, by making it play situations which are more difficult to memorize, just by playing randomly in the beginning. We did not implement such an algorithm (it is a non-trivial task as we should play randomly, but not too much, as the program must nonetheless have a reasonably good position), but we tested the memorization ability depending on whether situations were real or randomly drawn (in section IV-B we will consider non-standard opening moves for puzzling the human player). Results are presented in Table III.

\section{RESUlTS OF THE SSCI 2011 HUMAN VS COMPUTER GAMES IN PARIS: PROFESSIONAL GO PLAYERS}

Games were played with 30 minutes per side. C.-H. Chou commented that in $9 \times 9$ he can play without loss of performance. MoGoTW won 3 out of 4 games. Games are presented in Table 2, 3, 4, 5 .

For comparison, 10 games were played against various professional players of various ranks the 9th of March; MoGoTW, at that time, was playing as white only (the easier side, by far) and won only 3 out of 10 games; wins as black are in fact rare wins[10]. This difference suggests that pro players were weaker in blind Go; however, the sample size (10 games in standard 9x9 Go, 4 in blind go) is clearly not sufficient for concluding. 


\begin{tabular}{|c|c|c|}
\hline Case & $\begin{array}{c}\text { Average number } \\
\text { of correct stones }\end{array}$ & $\begin{array}{c}\text { Frequency of full } \\
\text { memorization (no error) }\end{array}$ \\
\hline $\begin{array}{c}\text { Random positions } \\
\text { (9 positions, 45 stones) }\end{array}$ & 3.2 & $11.1 \%$ \\
$\begin{array}{c}\text { Real positions } \\
\text { (10 positions, 50 stones) }\end{array}$ & 4.3 & $60.0 \%$ \\
\hline
\end{tabular}

TABLE III

WE RANDOMLY GENERATED POSITIONS WITH 10 STONES, AND COMPARED THEM TO GNUGO OPENINGS WITH 10 STONES. THE AMATEUR PLAYERS VIEW POSITIONS DURING 3 SECONDS (FULL SCREEN), AND THEN THEY MUST GIVE THE POSITIONS OF THE BLACK STONES. THEY KNOW IN ADVANCE THAT THEY HAVE TO MEMORIZE ONLY THE BLACK STONES. THESE POSITIONS ARE IN 9X9 GO. POSITIONS WERE TESTED IN RANDOM ORDERS. THE P-VALUE OF THE DIFFERENCE IS $1.7 \%$ (AVERAGE NUMBER OF CORRECT STONES, ASSUMING INDEPENDENCE BETWEEN EACH STONE MEMORIZATION) $1 \%$ (FREQUENCY OF FULL MEMORIZATION). (P-VALUES ARE COMPUTED BY FISHER'S EXACT TEST; POSITIONS ARE PRESENTED IN FIG. 1.)

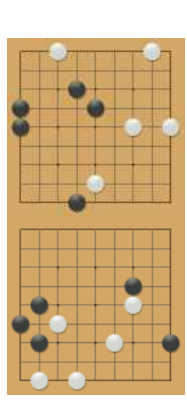

Random positions
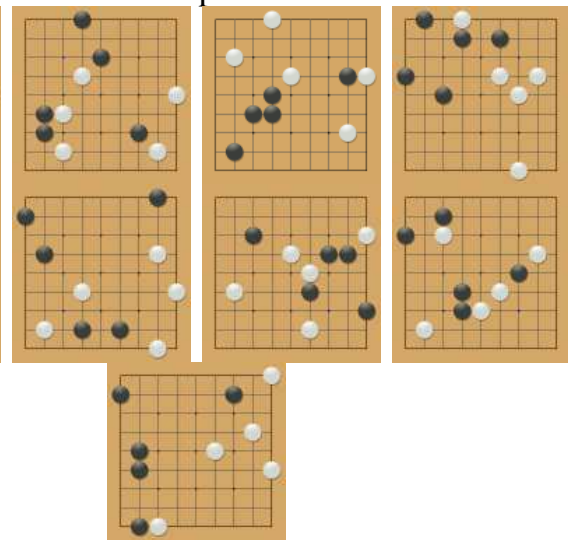

Real positions
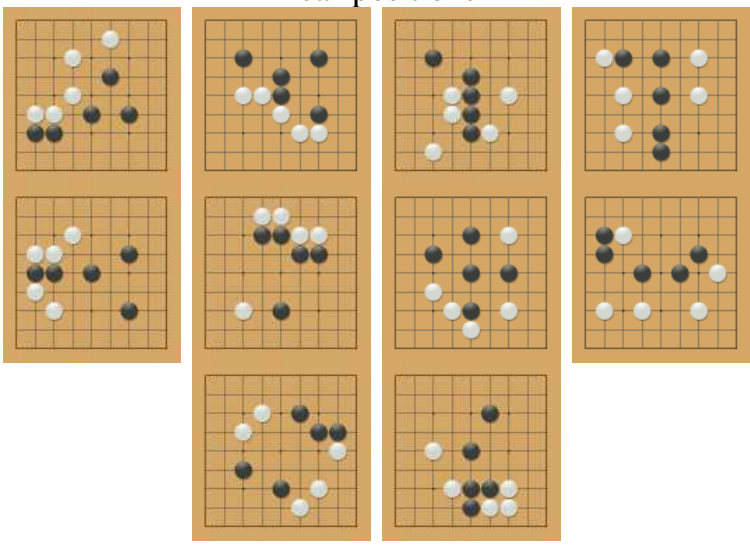

Fig. 1. Figures used for memorization experiments. We guess that Go players will guess that they can memorize the real games (bottom) much more than random games (top).

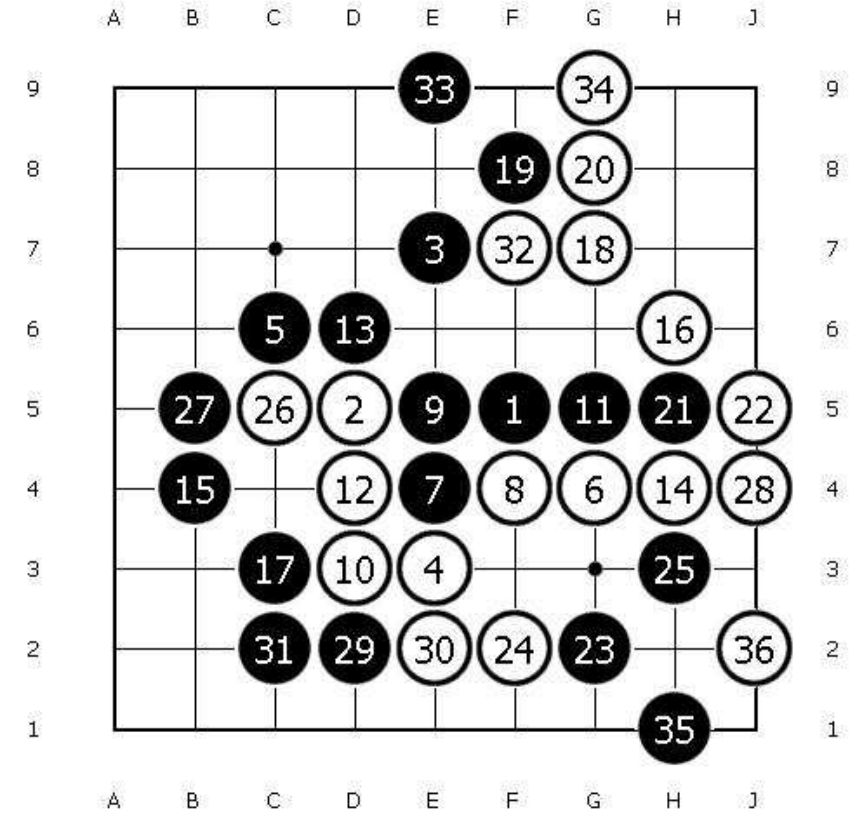

Fig. 2. Game won by MoGoTW as white against C.-H. Chou (9P). C.H. Chou said that MoGoTW played well; good symmetry-based opening (termed Manego). The human professional player tried some special moves for winning but MoGoTW made no mistake. C.-H. Chou says that playing blind is not a trouble, but it takes more time, as he must double-check every move. MoGoTW was running on a cluster of 3 nodes with 8,8 and 24 cores respectively.

\section{MAKING A Go PROGRAM SPECIFICALLY FOR BLIND Go}

We will here see two different modifications for blind computer board games: adding complicated endgames (section IV-A), and symmetrizing/perturbing openings (section IV-B).

\section{A. Adding complicated endgames}

We have seen above that playing natural moves in the endgame is not a good idea, as such moves are easy to memorize. Therefore, it's better to try complicated moves. In MoGoTW, end games moves which are easy to solve with eyes are forbidden by an early-resign rule: resign as soon as no move has more than $20 \%$ success rate; it is known that it does not change anything as these late moves are easy to understand when playing with eyes opened. We here test what happens if we remove this rule, and use a 5\% resign threshold.

Results are presented in Table I; condition 1 is the initial version of MoGoTW, whereas condition 2 is modified as proposed above. Conditions 1 and 2 are equivalent in standard Go, but very different in blind Go.

If we look at the results of amateur player \# 1 in $5 \times 5$ blind Go it seems the program is much stronger in the condition 2 case. For amateur player \# 2 (too strong for $5 \times 5$ ) there is no difference in $5 \times 5$ (Table I). The same experiment has then been reproduced in $7 \times 7$ blind Go for player \#2. In that case, with the help of the visual support, this amateur player won almost all its games against the program in its standard 


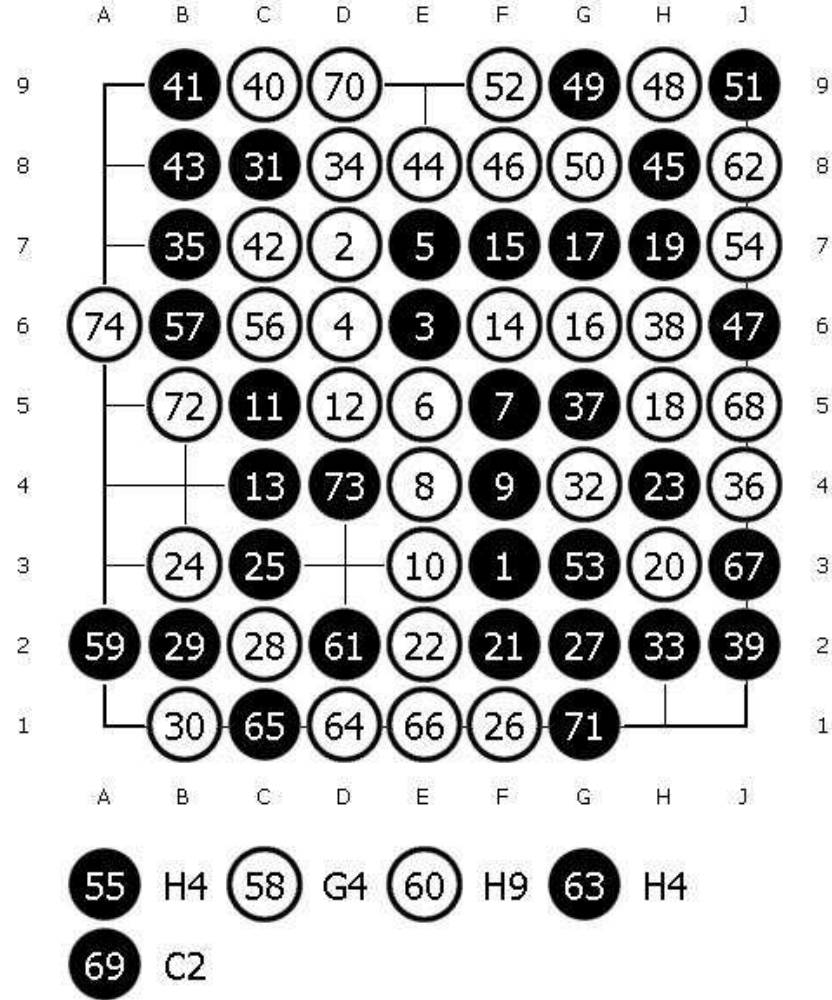

Fig. 3. Game won by MoGoTW as white against P.-C. Chou (5P). MoGoTW was running on a cluster of 10 nodes with 8 cores each. Black's move $\mathrm{H} 8$ (number 45 ) is the mistake (after Black H8, there could be a complex ko, but Black had no enough ko threats, and looses the game): J6 would be much better. The human player would have played better if it was not blind go (this mistake is not possible for a pro unless the game is blindfolded). As many Monte-Carlo Tree Search programs, MoGoTW played strange moves at the end, giving up territory (white 72 should be D4 or D3 instead of B5 and white74 should be D3 instead of A6); however, this does not change the final result of the game.

version (condition 1, with early resign), but lost the two games he played against the program with late resign $(5 \%$ threshold). Amateur player \#2 played correctly the beginning and the middle part of the games but started to loose track of the position when the program started to play some unusual moves and the human did not remember where he should play for securing his groups. Games are presented in Fig. 6.

\section{B. Symmetrizing and perturbing openings}

We will test first (i) symmetrizing openings (for perturbing the memory, without playing weaker moves) and then we will test (ii) weaker moves with more complicated consequences.

1) Symmetries: Go is obviously symmetrical (8 symmetries), but some symmetries are more usual (it is considered as more polite to play in a given corner). Many programs are also not symmetrical and prefer some moves than some others.

Amateur player \#1 played 15 games against gnugo in blind Go (with the qgo interface). The human was playing as black, and always started at the center. The human won everything but two games; he had preliminarily studied $5 \times 5$ Go and was

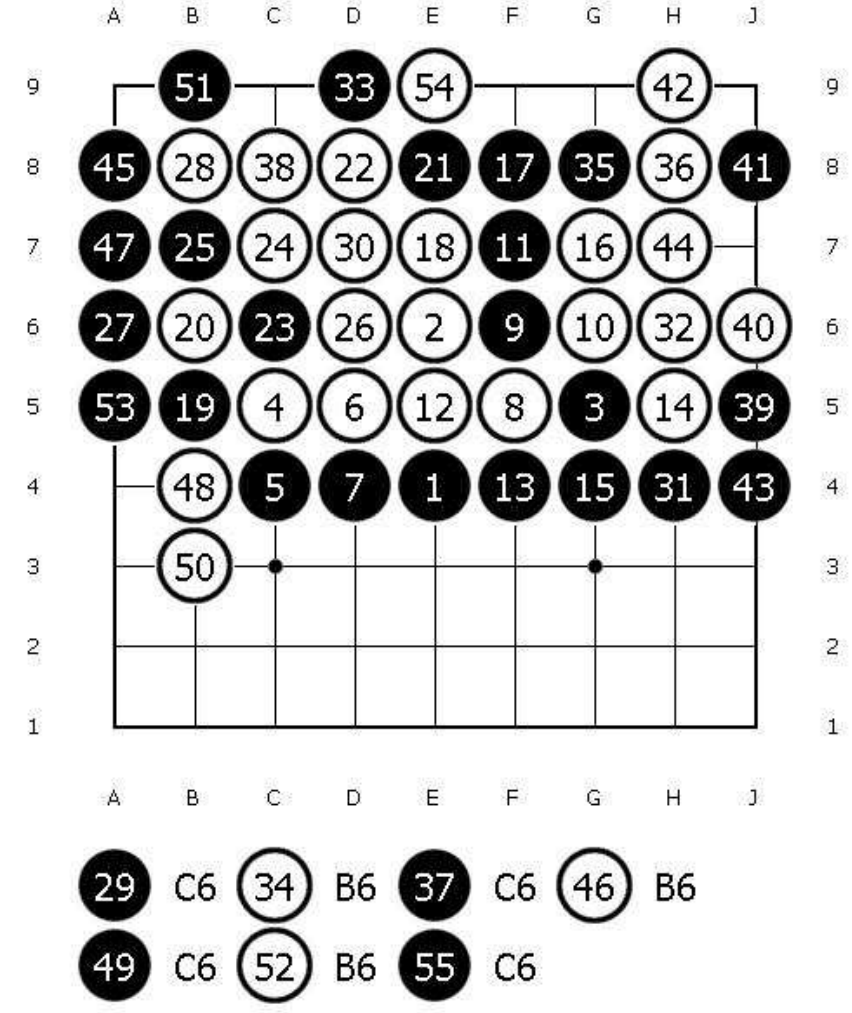

Fig. 4. Game won by MoGoTW as black against C.-H. Chou (9P). MoGoTW was running on a cluster of 3 nodes with 8,8 and 24 cores respectively. The human player said that black9 (F6) is an excellent move (amateurs would only consider F4 or G4 which are much more common patterns) and MoGoTW can win as black thanks to this very good move. The game is interesting even as a standard Go game; the rest of this caption is reserved for strong Go players as the analysis is difficult. F9 could limit the liberties of White E6, C5, D5 and F5. F9 could indeed cause an excellent sequence of Black moves: from 9th move to 29th move. After 29th move, Black had many ko-threats for the right White group, and would win the game. C-H Chou used about 20 minutes to contemplate next move after F6 (whereas he had only 30 minutes in a game). C-H Chou said that he could find the sequence from 10th move to 30th move and know that Black had many ko-threats for the white group on the right. He said when Black played at F6, he knew he lost.

playing in condition 1 , making the game much easier. He made a mistake in the beginning (game number \#4), and then won all games very quickly except game \#13. The interesting point is that game \#13 is the only one in which stone C2 was not played by white as the first or second move (see Fig. 7, left); it was therefore impossible for the human to come back to the pattern shown in Fig. 7 (right): it is only a symmetry of it and symmetries are not that easy in blindfolded games. Therefore, we conjecture that randomizing the opening is good (it can't harm anyway), but, more surprisingly, we also conjecture that playing a weaker move is a good idea because it's harder for humans. This suggests that playing something else than the Nash equilibrium might be a good idea.

2) Choosing weak openings: For testing this, we used the bad opening presented in Fig. 8 (left) instead of the standard opening in Fig. 8 (right); this is probably a bad opening, but we got results in Table IV, showing that the 

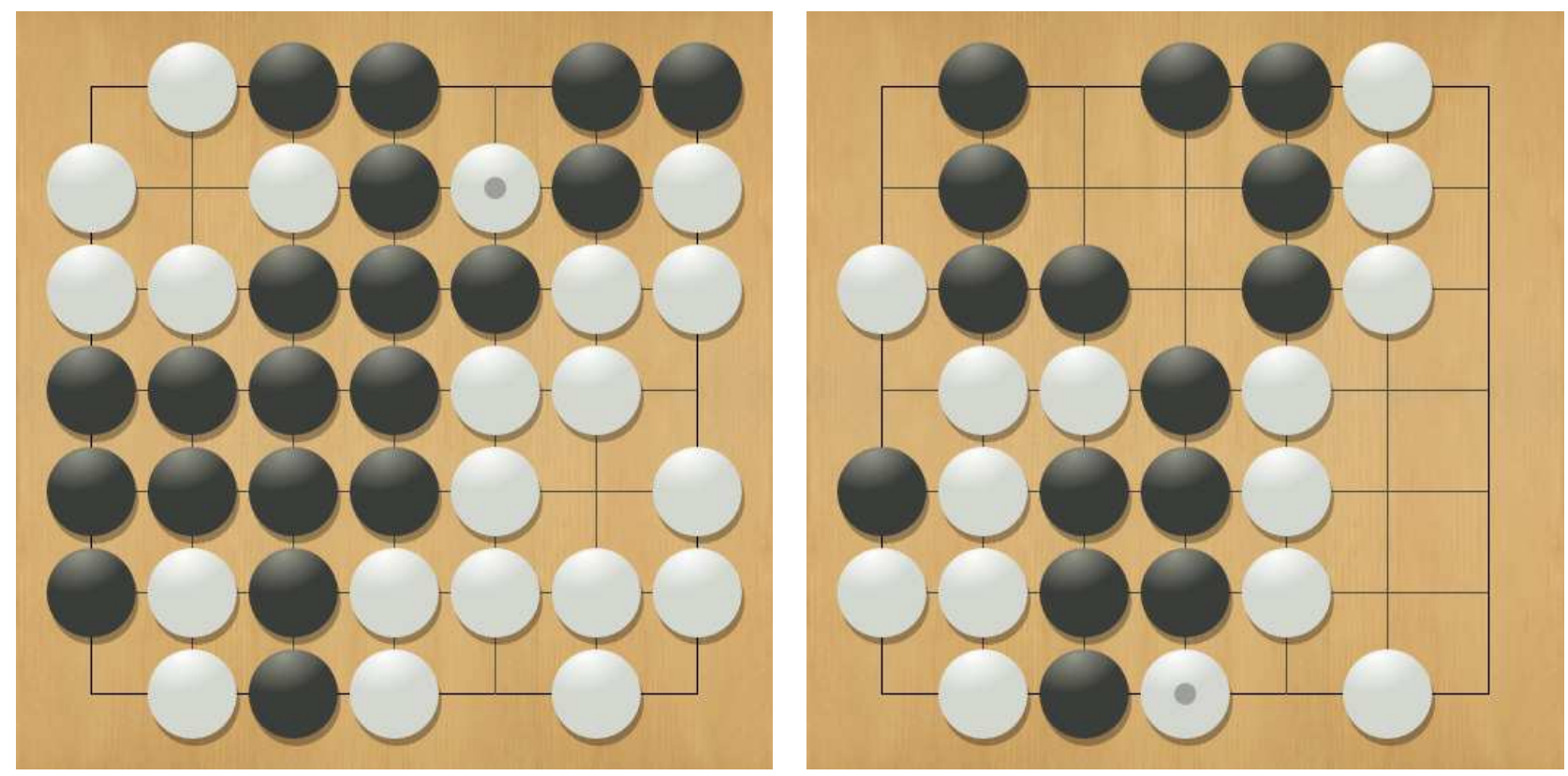

Fig. 6. The two games played by amateur \#2 in condition 2 (resign threshold at 5\%). Left: the human player was unable to remember the exact configuration for finalizing the win. Right: the human player lost in a more conventional sense.
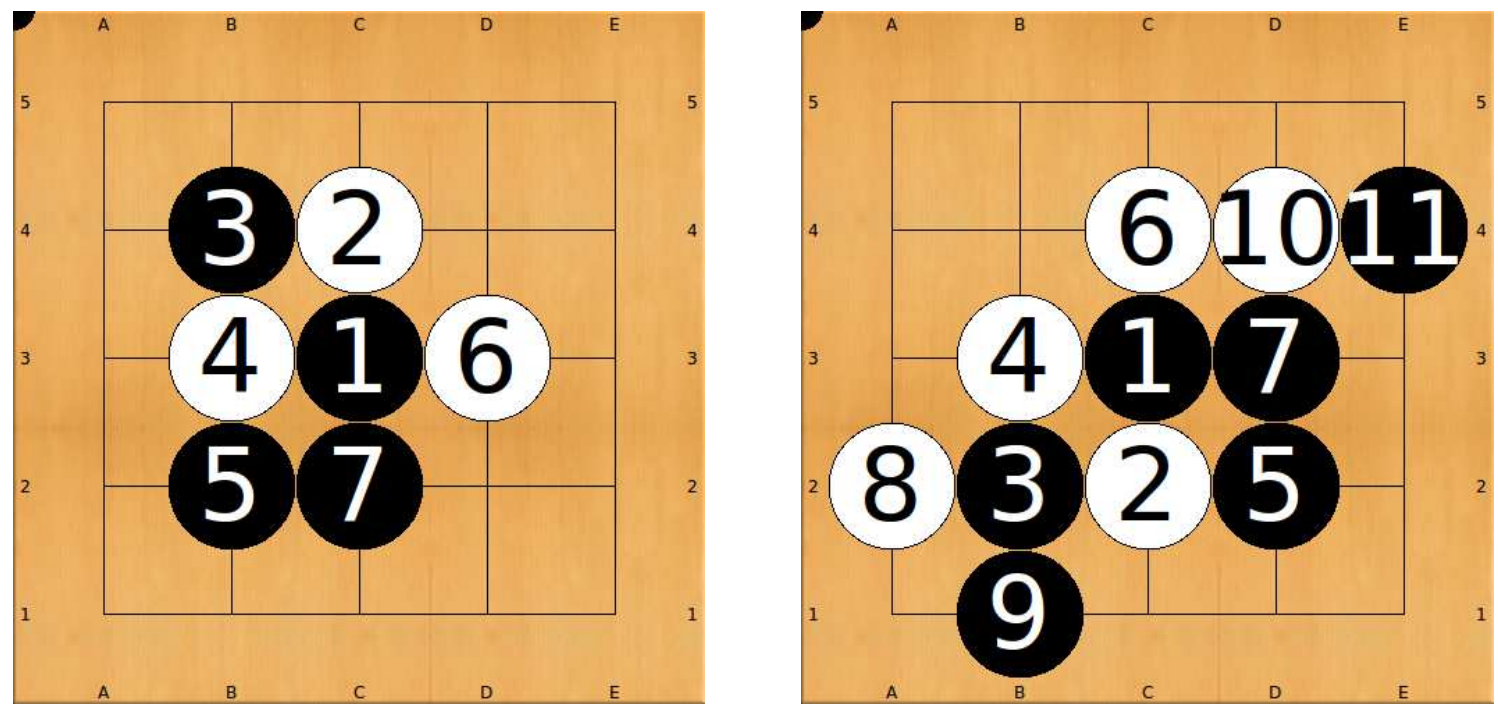

Fig. 7. Left: the game lost by the human in $5 \times 5$ in condition 1 in spite of careful analysis of $5 \times 5$ game before starting the games. Right: in all other games (15 games were played), the pattern was the same: the human captures the white stone in the bottom and then answers close to the next move (stone 11 makes stone 10 dead). As long as the opening includes $\mathrm{C} 2$ in one of the two first moves, the optimal strategy for white can be learnt just by two rules: threatening or capturing $\mathrm{C} 2$, and then answer E4 (if white D4) or A4 (if white B4).

more complicated situation is harder for humans.

\section{ANALYSis}

Our program played blind go games against strong human players. For the computer and at first view, this makes no difference; however, the results suggest that playing blind go is different from playing go, even if you have perfect memory (as a computer); one must play moves which lead to complicated outcomes, which are more difficult for the (human) opponent's limited memory.

Go is much more difficult than chess, in terms of blindfolded play. However, for the board size which is close to chess, it is true that strong players can play blind go with no special training; with a decay of performance, however.

Humans clearly emphasized that they need a visual support for playing blind Go; they use an empty board, with no stones on it, but with letters and number as coordinates. This is mentioned by many players; however, the best blind go players (able of playing on the 19x19 board) do not need this. In our experiments, the help of the support is not clear. In $5 \times 5$, results are slightly better for the amateur $\# 1$, but the difference is not significant. More games are needed. For the amateur number $\# 2$, there is no difference in size $5 \times 5$, but in 


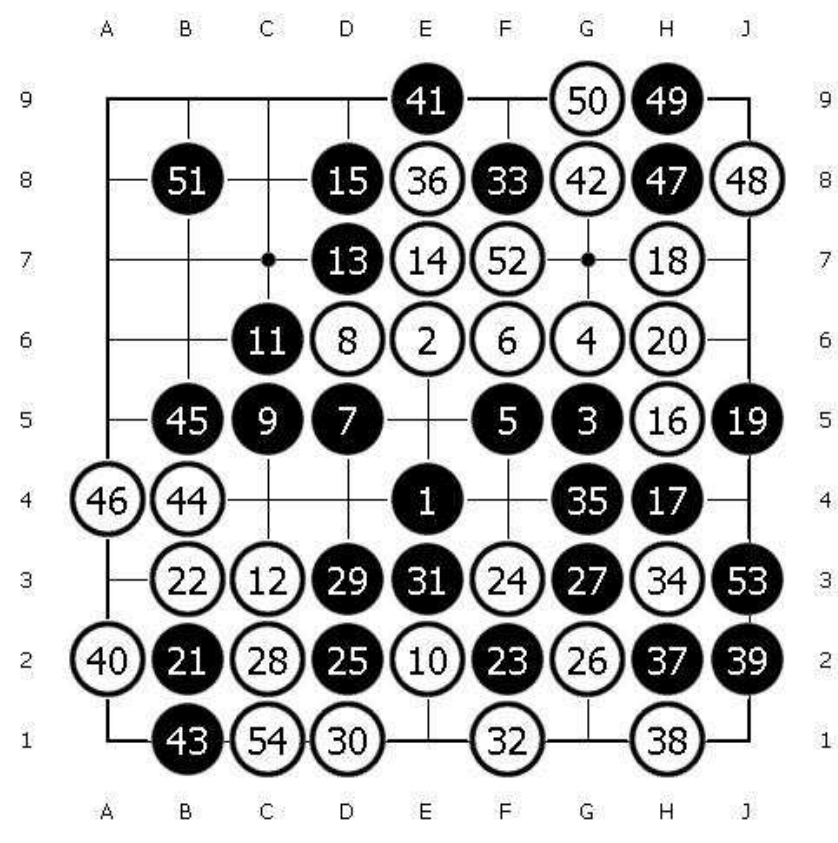

Fig. 5. Game lost by MoGoTW as black against P.-C. Chou (5P). MoGoTW was running on a cluster of 10 nodes with 8 cores each. P.-C. Chou said that this game is interested in terms of blind go. The human played the opening correctly, leading to a bad situation for computer-black (moves 4 to 10). Then, white 12 should have been C7 (and then black B7, white C3, very good for white). There were mistakes also in the rest of the game; white 36 should be $\mathrm{H} 2$ instead of F8; also the computer-black move E9 is not good (H8 would be much better): in the endgame, if MoGoTW(black) had played complicated moves it could have won by making the game too complicated for blind Go, but it played as in standard Go - the game was therefore natural and human-black could keep his advantage until the end and win.

\begin{tabular}{|c|c|c|c|}
\hline Case & $\begin{array}{c}\text { Result } \\
\text { for the bot }\end{array}$ & Case & $\begin{array}{c}\text { Result } \\
\text { for the bot }\end{array}$ \\
\cline { 2 - 4 } $\begin{array}{c}\text { Standard } \\
\text { opening }\end{array}$ & $\begin{array}{c}6 \text { losses } \\
\text { in a row }\end{array}$ & $\begin{array}{c}\text { Standard } \\
\text { opening }\end{array}$ & $\begin{array}{c}4 \text { wins } \\
\text { out of } 5^{*}\end{array}$ \\
\hline $\begin{array}{c}\text { Strange } \\
\text { opening }\end{array}$ & 3 wins & $\begin{array}{c}\text { Strange } \\
\text { opening }\end{array}$ & $\begin{array}{c}2 \text { win, } \\
4 \text { losses }\end{array}$ \\
\hline
\end{tabular}

TABLE IV

LEFT: RESULTS IN 6X6 BLIND GO WITH AMATEUR PLAYER \#1. THE GAMES WITH THE STANDARD OPENING WERE PLAYED FIRST. THESE RESULTS ARE CLEARLY NOT SUFFICIENTLY DIVERSIFIED FOR BEING

CONSIDERED AS A PROOF, BUT THEY SUGGEST THAT PLAYING A NON-STANDARD OPENING (LIKE IN FIG. 8, LEFT) MIGHT BE A GOOD IDEA FOR SOMEONE WITH PERFECT MEMORY (E.G. A COMPUTER) AGAINST A HUMAN OPPONENT. RIGHT: RESULTS IN 7X7 BLIND GO

WITH AMATEUR PLAYER \#2; THE STRANGE OPENING FOR THE COMPUTER AS WHITE IS D4 E5 D5 C3 (AS FOR THE 6X6 CASE WITH AMATEUR PLAYER \# 1 , THIS INVOLVES TWO GROUPS. THE LOST GAME IS SHOWN IN FIG. 9. RESULTS WITH A * ARE THOSE FROM A PREVIOUS TABLE, PLUS NEW RESULTS. GAMES WITH THE STRANGE OPENING ARE PLAYED AFTER THE STANDARD OPENING.

size $7 \times 7$ the help of the support seems to be really important.

Considering the games played as white, MoGoTW won 2 games out of 2 in blind Go the 13rd of April, whereas it only won 3 games out of 10 in standard Go the 9th of March. This is not a fair comparison as MoGoTW is in constant improvement; however, there was no big breakthrough
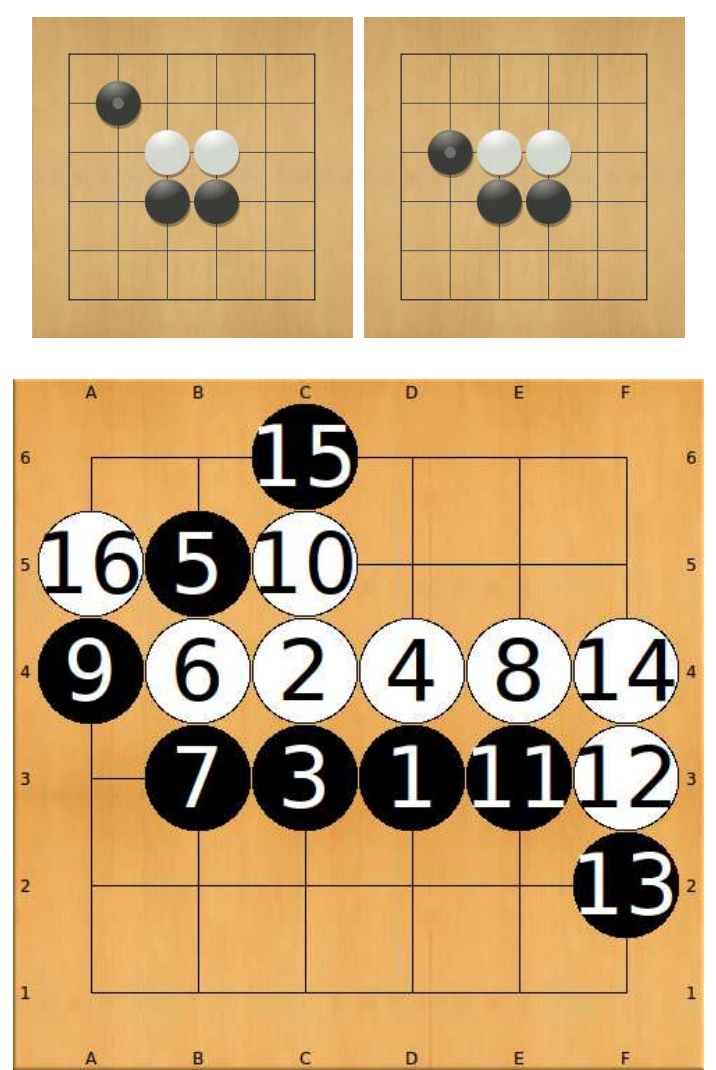

Fig. 8. Non-standard 6x6 opening (top left), aimed at puzzling a human opponent in blind Go; this opening is not as standard as the top right one. Bottom: a typical game with this non-standard opening and in which the human could not understand what was happening due to the non-standard situation (human white can still attack, but he had forgotten the current situation.

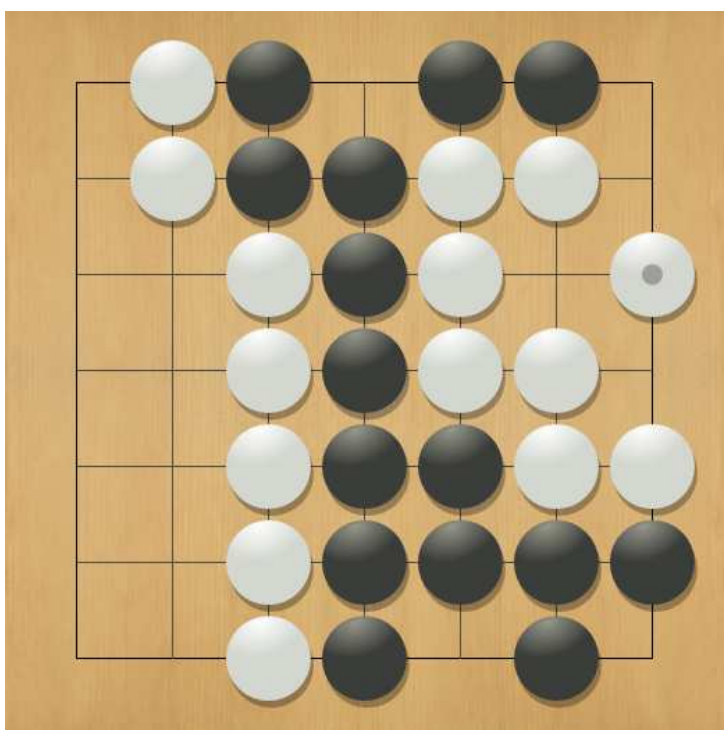

Fig. 9. Lost game in 7x7 with the non-standard blind-go opening D4 E5 D5 C3. This opening is probably not that good in standard Go, but leads to more sophisticated situations and longer games in blind Go, making it hard for human players. 
between the two sessions (March 9th and April 13th). From a statistical point of view, the $p$-value for comparing $2 / 2$ and $3 / 10$ (one-sided test) is $10 ! \times 5 ! /(3 !)=5 / 33=0.15152$, but this does not take into account the progress made by MoGo in the mean time. On the other hand, the feeling by human player (for some games) confirms that playing blind go is not fully equivalent to playing standard go, in particular when the situation becomes intricate; this suggests that humans (with very good memory) or computers could win more games by playing moves which make the situation very complicated and difficult to memorize. We have clearly shown this for the endgames (section IV-A) but could not completely prove it in the openings (section IV-B). We will soon test 19x19 games against one of the very rare human players able of doing this; from the level of Go players (even in blind Go) compared to computer-Go players, humans should win easily; however, as computers play unexpected moves maybe the situation will be more difficult for human blind-go players than when they play against humans. Maybe computers can be very difficult opponents in 19x19 by playing non-standard openings (increasing the number of groups); a minima, it seems reasonable to diversify the openings (in terms of symmetry) in order to make memorization more challenging for humans in case of repeated play; we conjecture also that playing weaker but hard to memorize moves might be a good idea (section IV-B for preliminary experiments around this).

We consider that the rules of blind Go must allow the human player to replay an illegal move. This is because games should be longer than in usual Go (no early resign), because keeping in memory the precise moves required for making a group definitely alive is a part of blind Go; but the game would become a dirty "rote learning" exercise if it was necessary for the human player to keep in memory all the locations of the stones, even those which are now useless for the game.

\section{CONCLUSION}

Regarding the questions emphasized in our abstract:

- Level of Go players. The level of Go players when playing blind 9x9 Go is very bad for beginners (not able to play a complete game); on the other hand strong players don't need a specific training provided that they have some visual support. However, the decay of performance decreases, but not vanishes, as the level of Go players improve; even strong Go players can make mistakes in the endgame in blind Go. Go players clearly state that they do not use a "brute" visual representation in mind, and that they use the meaning of moves and some patterns. Maybe there are nonetheless plenty of specific cases, as some people are more "strategic" memorizers and others are more "natural" memorizers. Investigating the case of very strong blind Go players, who don't need any visual support even in 19x19 (e.g. Bao Yun) would be interesting (see [6] for an investigation on people with huge memory, far from Go however).
- Importance of visual support. The quality of the visual support (i.e. of the empty board) is crucial according to many players. However, some humans with training are able to play complete 19x19 games with no support; this is not the case however for traditional players, who are used to simulate games in their mind's eye but with visual support and who strongly prefer to have an empty board available. However, on our numbers (mostly with no time limit for humans), the efficiency of having a secondary board is not always validated; it seems to be inefficient for some players and very efficient for others.

- Blindfolded-specific computational intelligence. A program should not resign too early in blind Go, as humans can make big mistakes in the end. This is illustrated by the game in Fig. 5; the computer might have won by making the game more difficult to memorize. Also, results in section IV showing that humans can loose in spite of a very good position due to insufficient memorization. The usual thresholds in Monte-Carlo Tree Search algorithms (resigning when the success rate is below 20\%) is too high; it's best to wait for a position in which the opponent has made all groups clearly alive or clearly dead; the threshold $5 \%$ is seemingly ok $(0 \%$ is not that tedious as once groups are secured the success rate drops to $0 \%$.). A less trivial modification consists in choosing non-standard opening (section IV-B) so that the situation is more sophisticated and the game is longer, so that memorization is more a challenge.

- Rules of blindfolded Go. The point above might suggest that blind Go becomes a stupid game in which a player with good memory is just waiting for an illegal move by his opponent for winning. For making the games interesting, we therefore decided to allow illegal moves - when the move is illegal, then just replay (as in phantom-games). With these rules, you just have to secure your groups, and then you can just pass until your opponent passes as well. This way, games are both convenient for humans and make the point that you should keep in memory all the information you need for securing all your groups.

Some further works are checking if there are highly different profiles of blind Go players; the fact that some very strong blind Go players do not need any visual support suggest that the top of the blind Go players have a special ability for being independent of visual stimuli. Another important question is the pedagogical effect of blindfolded games: playing blind Go is certainly a good way of becoming a strong blind Go player, but, as a side effect, does playing blind Go (or blind chess) enhance one's memory for other purpose? To the best of our knowledge, this important pedagogical question has not yet been investigated. A last further work is the more intensive testing of questions treated here: we got very good results in blind Go against humans, but this is only on 4 games; also, what happens in 19x19; also, confirming the positive impact of an empty board; finally, the tricks proposed here for improving programs for blind games (randomly 
choosing between the various symmetrical moves instead of always choosing the same one; playing longer games in order to benefit from the cases in which a part of the board was forgotten by the human player; and, most surprising, playing unnatural weak moves (i.e., not playing the Nash moves!) for making the game difficult to memorize) should be checked more thoroughly.

Acknowledgements: We are grateful to Grid5000 for support in parallel versions of the algorithms, including the gridbased opening book development. The authors would like to thank the National Science Council of Taiwan for financially supporting this international cooperation research project under the grant NSC 99-2923-E-024-003-MY3. Additionally, this work was supported by the French National Research Agency (ANR) through COSINUS program (project EXPLO-RA ANR-08-COSI-004).

\section{REFERENCES}

[1] M. Boutin, "Les jeux de pions en france dans les années 1900 et leurs liens avec les jeux étrangers. l'invention d'un jeu singulier : l'attaque," in Proceedings of BGA'2010, 2010.

[2] P. Saariluoma, "Aspects of skilled imagery in blindfold chess." Acta psychologica, vol. 77, no. 1, pp. 65-89, Aug. 1991. [Online]. Available: http://view.ncbi.nlm.nih.gov/pubmed/1950637

[3] V. Jeremic, D. Vukmirovic, and Z. Radojicic, "Does playing blindfold chess reduce the quality of game: Comments on chabris and hearst (2003)," Cognitive Science, vol. 34, no. 1, pp. 1-9, 2010.

[4] S. Riis, "Ai and how chess taught us humility," in Bielefeld's seminar on Search Methodologies, 2010.

[5] O. Schulzyk, J. Bongartz, T. Bildhauer, U. Hartmann, and R. Herpers, "A real bicycle simulator in a virtual reality environment: The fivis project," in ECIFMBE- BMT Conference, IFMBE Proceedings 22, J. V. S. et al, Ed. Antwerp, Belgium, Springer, 2008, pp. 2628-2631.

[6] J. Wilding and E. Valentine, "Memory champions," British Journal of Psychology, vol. 85, no. 2, pp. 231-244, 1994. [Online]. Available: http://dx.doi.org/10.1111/j.2044-8295.1994.tb02520.x

[7] G. Cermak, "Short-term recognition memory for complex free-form figures," Psychonomic Science, vol. 25, no. 4, pp. 209-211, 1971.

[8] N. Cowan, "The magical number 4 in short-term memory: A reconsideration of mental storage capacity," Behavioral and Brain Sciences, vol. 24, no. 1, 2001.

[9] V. L. I.G. Sligte, H.S. Scholte, "Are there multiple visual short-term memory stores?" PLOS ONE, vol. 3, no. 2, 2008.

[10] S. Billouet, J.-B. Hoock, C.-S. Lee, O. Teytaud, and S.-J. Yen, "9x9 Go as black with komi 7.5: At last some games won against top players in the disadvantageous situation," ICGA Journal, 122009. [Online]. Available: http://hal.inria.fr/inria-00528770/en/ 